\title{
Belgium
}

\section{Hospital Libraries}

National Societies' interest in working out and implementing in their own countries programmes intended to improve not only the physical but also the moral condition of hospital patients is well known.

The International Review has several times mentioned the initiative taken by the Red Cross in this field, such as the organizing of distractions of an artistic nature in hospitals, therapy through distraction in institutions for the mentally sick, the introduction, particularly in convalescent establishments, of handicrafts. Hospital libraries services are also an important part of these efforts and we think readers will be interested in the following article in which the Countess I. G. Du Monceau de Bergendal explains how books are selected by the Belgian Red Cross libraries for hospitals. ${ }^{1}$

This Society's work in this field has been increasing. In 1967 it set up 13 new libraries, bringing the total of libraries with which it is concerned to 109. The following figures for the same period are also of interest: in one year, more than 5,000 new books were chosen and catalogued; nearly 22,000 were lent out in 86 institutions; 595 critical review cards were issued by the Reading Committees; more than 4,000 books and albums were bound. The libraries were active in civilian and military hospitals, homes for the aged, for the mentally sick, and in sanatoria.

The "Comité National des Bibliothèques d'Hôpitaux" (C.N.B.H.) set up by the Belgian Red Cross in 1937, has a permanent central executive staff of qualified librarians, assisted by 500 voluntary workers. The latter, aged from 18 to 60 years, distribute books at least once a week in 114 civilian and military hospitals, maternity wards, institutions for the mentally sick and homes for the elderly.

${ }^{1}$ From the official publication of the Belgian Red Cross: Mieux-Vivre, Brussels 1968, No. 4. 
Although the women distributing the books are of exemplary good will, they cannot always have read everything they distribute. We considered we should give them the chance of acquiring a general idea of the contents of all the books they distribute and that they should be enabled to keep abreast of the various categories of latest issues.

We also wanted those running the distribution services to be able to give knowledgeable advice, that is to say suitable to the intellectual standard of the borrowers. We do not try to educate the sick whilst they are in hospital, but neither do we wish to discourage them by offering them books which are too great a strain on the intellect. We prefer to arouse their interest for reading whatever their standard may be and thus divert them from their own personal problems.

During book distributions we realised that not all books are suitable to all patients. Some books are suitable to none of them and we have been required systematically to eliminate those which are critical of hospitals, describe sicknesses in detail, or undermine the confidence which a patient must have in his doctor.

Two categories of patient require special choices: tuberculosis cases and the mentally sick.

In sanatoria we avoid books which mention death by tuberculosis and also novels which are too sensuous for patients whose illness makes them abnormally sensitive in this respect.

In institutions for the mentally sick, we avoid books which cause worry or abnormal excitement, that is to say dealing with excessive mysticism, suicide, sexual perversion, introspection, none of which can have a good influence when psychic equilibrium is disturbed.

In the most usual case, when no censorship is called for, we desire to be able to draw the attention of the circulating library staff to demoralising books so that they may forewarn the reader.

As can be seen, it was for essentially practical reasons that we thought we must set up book selection committees

We know of course that in some countries it is held that the patient like any other citizen is entitled to read what he wants and make his own judgment with full knowledge of the issue and free of censorship. We know also that the patient may have books 


\section{IN THE RED CROSS WORLD}

brought to them by relatives, but we do not wish to take the responsibility of giving out books which might depress a patient whose attention is already centred about his own problems due to his illness itself.

We even go further in that we never distribute under the sign of the Red Cross reference books, medical dictionaries or technical works on illnesses. All these books soon go out of date and are always liable to conflict with the viewpoint of the doctor in charge of a case. In addition, we all know from experience that reading a medical dictionary can add imaginary to the genuine symptoms.

Following the Edinburgh meeting of the International Federation of Librarians' Associations we discussed in Belgium whether it was or was not useful to give patients technical works of real value to teach them to live with their illness. We came to the conclusion that this type of book should not be distributed through our services, but by the doctor if he deemed it expedient.

To carry out this study of books with an eye to patient welfare, we have therefore set up French and Flemish Reading Committees and we have little by little adopted standards which facilitate and co-ordinate the work of the Readers' Committees.

These Committees, which meet on the average once a month, consist of a score of readers. They are chosen for their interests and special knowledge in literature from among the distributors having several years service in hospitals, which gives them an insight into the psychology of the patient. We also prefer that they continue distributing in hospitals in order to maintain contact with borrowers.

Each member of the Committee reads at home several books chosen at meetings and appropriate to her personal taste and qualifications. Each book is read by two members.

The members each complete a standard form which they read aloud, point by point, to the following meeting of the Committee. The two points of view are compared heading by heading and should coincide. If the two members do not agree a third acts as referee and decides the issue during fresh discussion at a further meeting. The Reading Committee members sign and date these forms.

The two initial forms are merged in a single index-card. These index-cards are then used to form a reference catalogue at the 
central library which is consulted for the compiling of new library collections and for bringing existing libraries up to date.

At the end of each year the Central Library technicians draw up a list, with comments, of books recommended by the French and Flemish Reading Committees. This list is then sent to the various libraries.

The French Committee of the C.N.B.H. also co-operates in the work of the library service of the Ministry of National Education which each year entrusts it with the criticism of a number of books. These appraisals are then included in the Ministry Library Index for use in the country's public libraries.

The Reading Committees started in 1945. After 23 years, we have 20,000 books on our index.

Of all books appraised, $2 \%$ were considered completely unsuited, $7 \%$ were approved, subject to reservations for general medical reasons, $5 \%$ were deemed unsuited for sanatoria, and $9 \%$ were eliminated from the choice available to mental patients. 